\title{
ВЗАИМОСВЯЗЬ АГРЕССИВНОСТИ И ЦЕННОСТНО-МОТИВАЦИОННЫХ ХАРАКТЕРИСТИК ЛИЧНОСТИ В СВЯЗИ С ИНВАЛИДНОСТЬЮ ПО ЗРЕНИЮ
}

\author{
Краснов А.В., Баширова Э.Э.
}

Цель. Изучить взаимосвязь агрессивности с иенностно-мотивационныли характеристиками у лиц с инвалидностью по зрению в связи со временем наступления инвалидности.

Методы или методология проведения работы. В исследовании принял участие 61 инвалид по зрению, 32 человека с врожденной инвалидностью и 29 - с приобретенной. Методы диагностики - «опросник Басса-Дарки», опросник М. Рокича «Ценностные ориентации», методика Е.Б. Фанталовой «Уровень соотношения «иенности» и «доступности» в различных жизненных сферах». Собранные данные обрабатывались с помощью коэффициента ранговой коррелящии Спирмена и U-критерий Манна-Уитни.

Результаты. Лица с врожденной инвалидностью по зрению обладают более низкими показателями агрессивности, чем лища с приобретенной инвалидностью. Для лиц с врожденной инвалидностью по зрению более значимы цеенности, центрированные на самореализации, тогда как для лиц с приобретенной инвалидностью - иентрированные на приспособлении к группе. Каждая из исследуемых групп обладает специфическими корреляционными взаимосвязями показателей агрессивности и уровня дезинтеграции ценностно-мотивационной сферы.

Область применения результатов. Результаты исследования могут быть применены в практике психологического консультирования, будут иметь практическую значимость для специиалистов, работающих с инвалидами по зрению. 
Ключевые слова: агрессивность; инвалидность; слепота; иченности; мотивы.

\title{
ASSOCIATION OF AGGRESSION, VALUES AND MOTIVES OF VISUALLY IMPAIRED PEOPLE
}

\author{
Krasnov A.V., Bashirova E.E.
}

Purpose. Explore of the association between aggression, values and motives of visually impaired people.

Methodology. The sample consists of 61 visually impaired people: 32 people with congenital disabilities and 29 with acquired disabilities. Methods: Buss-Durkee Hostility Inventory (BDHI), Rokeach Value Survey (RVS), techniques "Level of correlation of value and accessibility in different life spheres» (E.B. Fantalova). Statistical methods: Spearman's rank correlation coefficient, Mann-Whitney U-test.

Results. People with congenital vision disabilities have lower rates of aggressiveness than people with acquired disabilities. For persons with congenital visual disability, values centered on self-realization are more significant, whereas for persons with acquired disabilities, values are more centered on adaptation to the group. Each of groups has specific correlation associations between indicators of aggression and the level of correlation of value and accessibility.

Sphere of implementation of the results. Results can be applied in practice of psychological consultation, they can have practical importance for experts working with visually impaired people.

Keywords: aggression; disability; blindness; values; motives; visually impaired.

\section{Введение}

Инвалидность может существенно изменить жизненный путь человека и нарушить процесс социализации. По разным оценкам от 90\% до 95\% информации человек получает с помощью зрения [12], с его помощью формируются представления о предметах и 
явлениях, познаются существенные признаки объектов, осуществляется ориентация в пространстве и контроль за движениями [2]. Не удивительно, что слепота может способствовать преобладанию астенических, подавляющих активность индивида настроений тоски, грусти, либо повышенной раздражительности, аффективности, также может приводить к развитию негативных черт характера, таких как негативизм, внушаемость, агрессивность, конформность, обидчивость, подозрительность, схематичность в оценке людей [3]. Подобные данные получены в ходе исследований поздно ослепших людей, тяжело переживающих утрату зрения [15]. Можно предположить, что личностные особенности и стиль межличностного общения людей, ослепших во взрослом возрасте и людей, обладающие инвалидностью с детства, будут достаточно резко различаться, так как люди больные с рождения или с самого раннего детства сразу оказались в условиях ограничения своих физических возможностей $[4,6,14]$.

У людей с ограниченными возможностями здоровья, заболевшими или получившими травму во взрослом возрасте, жизнь резко разделилась на «до» и «после» болезни [13]. Они оказались на перепутье, совершенно не готовыми к новому образу жизни. Старые межличностные отношения подвергаются серьёзным испытаниям и часто прекращаются, семьи часто распадаются, установление новых межличностных связей представляет большую трудность. Их поведение, нередко, связанно с резкой сменой настроения, они предпочитают в межличностном общении стратегии противоборства и сотрудничества. Для них наиболее ярко выражены 4 типа отношения к окружающим: авторитарность, подозрительность, агрессивность и подчиняемость [7].

Люди с ограниченными физическими возможностями, получившие их с рождения или с самого раннего детства, в своем большинстве оказываются более способными к интеграции в общество, более контактными и с большим, хотя и сдержанным оптимизмом, смотрят в будущее [11]. Это объясняется тем, что «правила игры» были определены с раннего детства адекватным воспитанием, фор- 
мированием реалистичной оценки своего положения. Такие люди предпочитают в межличностном общении стратегию сотрудничества и компромисса. Наибольшие значение для них имеет дружелюбие, зависимость и подчиняемость $[6,10]$.

Проявление агрессивного поведения и тревожности у людей с дефектами зрения обусловлено прежде всего двумя причинами: с одной стороны, изолированностью и познавательными интересами, а с другой ограниченностью в передвижении. При этом уровень активности отражения при прочих равных условиях оказывается зависимым от степени тяжести дефекта и времени его появления. В ряде случаев инвалиды по зрению оказываются не в состоянии преодолеть возникающие перед ними препятствия. Многократное повторение фрустрации ведет к развитию агрессивности, безынициативности, отказу от деятельности.

Анализ научной литературы показал, что при всей изученности проблемы в целом, отсутствуют теоретически обоснованные данные, показывающие взаимосвязь агрессивности с ценностно-мотивационными характеристиками у лиц с инвалидностью по зрению в связи со временем наступления инвалидности. В настоящей работе проверяются следующие гипотезы.

Гипотеза № 1: уровень агрессивности лиц с приобретенной инвалидностью по зрению выше уровня агрессивности лиц с врожденной инвалидностью.

Гипотеза № 2: лица с приобретенной и врожденной инвалидностью по зрению характеризуются различными иерархиями ценностей.

Гипотеза № 3: лица с приобретенной и врожденной инвалидностью характеризуются различными взаимосвязями показателей агрессивности и уровня дезинтеграции в мотивационно-личностной сфере.

\section{Метод}

\section{Выборка и прочедура исследования}

В исследовании принял участие 61 инвалид по зрению, в возрасте от 22 до 63 лет $(\mathrm{M}=44,6 ; \mathrm{SD}=11,8), 28$ мужчин и 33 женщины. Основные характеристики выборки представлены в таблице 1. 
Таблиц̧а 1.

Характеристики выборки исследования

\begin{tabular}{|l|c|c|}
\hline \multicolumn{1}{|c|}{$\begin{array}{c}\text { Характеристики } \\
\text { выборки }\end{array}$} & $\begin{array}{c}\text { Врожденная } \\
\text { инвалидность }\end{array}$ & $\begin{array}{c}\text { Приобретенная } \\
\text { инвалидность }\end{array}$ \\
\hline Количество & 32 & 29 \\
\hline Средний возраст/ SD & $45,3 / 10,9$ & $43,8 / 12,8$ \\
\hline Мужчины & 12 & 16 \\
\hline Женщины & 20 & 13 \\
\hline Инвалидность 1й группы & 13 & 8 \\
\hline Инвалидность 2й группы & 12 & 8 \\
\hline Инвалидность 3й группы & 7 & \\
\hline
\end{tabular}

Примечание: в таблице указаны абсолютные показатели.

Исследование проводилось на базе «ПОО ВОС НУК» Реабилитационном Культурно-Спортивном Досуговом Центре Инвалидов г. Перми. Для всех испытуемых данное экспериментальное исследование происходило в индивидуальной форме. Участие в эксперименте было добровольным. Время выполнения не учитывалось.

В соотношении с нормативными показателями полученные результаты свидетельствуют о том, что обе группы обладают низким уровнем дезинтеграции ценностно-мотивационной сферы и низким уровнем враждебности и агрессивности (табл. 2).

Таблицьа 2.

Характеристики выборки по показателям дезинтеграции ценностно-мотивационной сферы, враждебности и агрессивности относительно нормативных показателей

\begin{tabular}{|c|c|c|}
\hline & $\begin{array}{c}\text { Врожденная } \\
\text { инвалидность }\end{array}$ & $\begin{array}{c}\text { Приобретенная } \\
\text { инвалидность }\end{array}$ \\
\hline \multicolumn{3}{|c|}{ Уровень дезинтеграции } \\
\hline Ниже нормы & 21 & 22 \\
\hline Норма & 11 & 3 \\
\hline Выше нормы & 0 & 4 \\
\hline \multicolumn{3}{|c|}{ Враждебность } \\
\hline Ниже нормы & 3 & 0 \\
\hline Норма & 20 & 22 \\
\hline Выше нормы & 9 & 7 \\
\hline \multicolumn{3}{|c|}{ Агрессивность } \\
\hline Ниже нормы & 28 & 22 \\
\hline
\end{tabular}


Окончание табл. 2.

\begin{tabular}{|l|c|c|}
\hline Норма & 2 & 7 \\
\hline Выше нормы & 2 & 0 \\
\hline
\end{tabular}

Примечание: в таблице указаны абсолютные показатели.

\section{Методы и методики исследования}

Организационный метод исследования - сравнительный (метод поперечных срезов). Сбор эмпирических данных осуществлялся с помощью психодиагностических методов. Собранные данные обрабатывались методами математико-статистического анализа (коэффициент ранговой корреляции Спирмена, U-критерий Манна-Уитни).

Для диагностики склонности к различным формам агрессивного поведения был использован «Опросник Басса-Дарки» [8].

Для выявления иерархии индивидуально разделяемых ценностей был использован опросник М. Рокича «Ценностные ориентации» [5].

Для диагностики рассогласования, дезинтеграции в мотивационноличностной сфере, степени неудовлетворенности текущей жизненной ситуацией, внутренней конфликтности, блокады основных потребностей, а также уровня самореализации, интегрированности, гармонии был использована методика Е.Б. Фанталовой «Уровень соотношения «ценности» и «доступности» в различных жизненных сферах» [9].

\section{Результаты}

Для проверки гипотезы №1 о том, что показатели агрессивности лиц с приобретенной инвалидностью выше показателей агрессивности лиц с врожденной инвалидностью был использован сравнительный анализ групп с помощью U-критерия Манна-Уитни (табл. 3).

Таблицุа 3.

Результаты сравнительного анализа показателей агрессивности групп с врожденной и приобретенной инвалидностью

\begin{tabular}{|l|r|r|r|r|c|}
\hline $\begin{array}{c}\text { Шкалы } \\
\text { методики }\end{array}$ & $\begin{array}{c}\text { Приобретен- } \\
\text { ная инва- } \\
\text { лидность }\end{array}$ & $\begin{array}{c}\text { Врождённая } \\
\text { инвалид- } \\
\text { ность }\end{array}$ & $\mathbf{U}$ & $\mathbf{Z}$ & $\begin{array}{c}\text { Уровень } \\
\text { значимо- } \\
\text { сти }\end{array}$ \\
\hline Косвенная агрессия & 1083 & 808 & 280 & 2,69 & $\mathrm{p}<0,01$ \\
\hline Негативизм & 1059,5 & 831,5 & 303,5 & 2,38 & $\mathrm{p}<0,05$ \\
\hline
\end{tabular}


Окончание табл. 3.

\begin{tabular}{|l|r|r|r|r|r|}
\hline Враждебность & 1062,5 & 828,5 & 300,5 & 2,37 & $\mathrm{p}<0,05$ \\
\hline Агрессивность & 1042 & 849 & 321 & 2,07 & $\mathrm{p}<0,05$ \\
\hline
\end{tabular}

Из таблицы видно, что лица с приобретенной инвалидностью характеризуются большим уровнем косвенной агрессией, негативизма, враждебности и агрессивности, чем лица с врожденной инвалидностью.

Для проверки гипотезы №2 о том, что лица с приобретенной и врожденной инвалидностью характеризуются различными иерархиями ценностей, был использован сравнительный анализ групп с помощью U-критерия Манна-Уитни (табл. 4).

Таблицуа 4.

Результаты сравнительного анализа рангов ценностей в иерархии ценностей групп с врожденной и приобретенной инвалидностью

\begin{tabular}{|l|c|c|c|c|c|}
\hline \multicolumn{1}{|c|}{ Ценности } & $\begin{array}{c}\text { Приобретен- } \\
\text { ная инвалид- } \\
\text { ность }\end{array}$ & $\begin{array}{c}\text { Врождённая } \\
\text { инвалидность }\end{array}$ & $\mathbf{U}$ & $\mathbf{Z}$ & $\begin{array}{c}\text { Уровень } \\
\text { значимо- } \\
\text { сти }\end{array}$ \\
\hline Удовольствие & 753,5 & 1137,5 & 318,5 & $-2,12$ & $\mathrm{p}<0,05$ \\
\hline Жизнерадостность & 697,5 & 1193,5 & 262,5 & $-2,93$ & $\mathrm{p}<0,01$ \\
\hline Исполнительность & 758,5 & 1132,5 & 323,5 & $-2,05$ & $\mathrm{p}<0,05$ \\
\hline Самоконтроль & 1067,5 & 823,5 & 295,5 & 2,44 & $\mathrm{p}<0,05$ \\
\hline $\begin{array}{l}\text { Смелость в отстаи- } \\
\text { вании своего мнения }\end{array}$ & 701 & 1190 & 266 & $-2,86$ & $\mathrm{p}<0,01$ \\
\hline Терпимость & 1056 & 835 & 307 & 2,27 & $\mathrm{p}<0,05$ \\
\hline
\end{tabular}

Примечание: в таблице представлены результаты относительно значимых различий по группам.

Из таблицы видно, что в иерархии терминальных ценностей у лиц с врожденной инвалидностью ценность удовольствия стоит выше, чем у лиц с приобретенной.

В иерархии инструментальных ценностей у лиц с приобретенной инвалидностью ценности жизнерадостности (чувства юмора), исполнительности (дисциплинированности) и смелости в отстаивании своего мнения стоят выше, чем у лиц с приобретенной, а ценности самоконтроля (сдержанность, самодисциплина) и терпимости (к взглядам и мнению других, умение прощать другим их ошибки и заблуждения) - ниже. 
Для выявления взаимосвязей между агрессивностью и уровнем дезинтеграции ценностно-мотивационной сферы был использован корреляционный анализ Спирмена (табл. 5).

Таблицуа 5.

Результаты корреляционного анализа Спирмена показателей агрессивности и ценностно-мотивационной сферы

\begin{tabular}{|c|c|c|}
\hline \multirow{2}{*}{ Показатели агрессивности } & \multicolumn{2}{|c|}{$\begin{array}{c}\text { Уровень дезинтеграции } \\
\text { мотивационно-личностной сферы }\end{array}$} \\
\hline & $\begin{array}{c}\text { Приобретенная } \\
\text { инвалидность }\end{array}$ & $\begin{array}{c}\text { Врожденная } \\
\text { инвалидность }\end{array}$ \\
\hline Косвенная агрессия & $0,62 * * *$ & \\
\hline Негативизм & $0,42 *$ & \\
\hline Обида & 0,59 *** & $-0,37 *$ \\
\hline Вербальная агрессия & $0,51 * *$ & \\
\hline Угрызения совести & & $-0,39 *$ \\
\hline Агрессивность & $0,4^{*}$ & \\
\hline
\end{tabular}

По результатам корреляционного анализа у лиц с приобретенной инвалидностью обнаружены прямые связи дезинтеграции в ценностно-мотивационной сфере с физической агрессивностью, косвенной агрессивностью, негативизмом, обидой, вербальной агрессией и агрессивностью в целом. У лиц с врожденной инвалидностью выявлены обратные связи дезинтеграции в ценностно-мотивационной сфере с обидой и угрызениями совести.

\section{Обсуждение результатов}

Согласно приведенным выше результатам лица с приобретенной инвалидностью характеризуются большим уровнем косвенной агрессией, негативизма, враждебности и агрессивности, чем лица с врожденной инвалидностью, что согласуется с данными, полученными ранее на выборках приобретенной и врожденной инвалидности по отдельности. В ряде случаев лица с приобретенной инвалидностью по зрению оказываются не готовы смиряться с новыми условиями жизни и формировать новый продуктивный стиль деятельности. Многократное повторение фрустрации ведет к развитию агрессивности, безынициативности, отказу от деятельности. 
Результаты сравнительного анализа иерархии терминальных и инструментальных ценностей в группах показывают, что для лиц с врожденной инвалидностью более значимы ценности, центрированные на самореализации, тогда как для лиц с приобретенной инвалидностью центрированные на приспособлении к группе. Так у первых на более значимых позициях находятся ценности смелость (ценность дела, индивидуалистическая ценность), исполнительность (ценность дела), удовольствие (ценность личной жизни), а у вторых - терпимость (ценность общения, альтруистическая ценность, ценность принятия других) и самоконтроль (ценность принятия других, конформистская ценность).

Интересны результаты корреляционного анализа показателей агрессивности и уровня дезинтеграции ценностно-мотивационной сферы. Каждая из исследуемых групп обладает специфическими корреляционными взаимосвязями. Если группа с приобретенной инвалидностью характеризуется тем, что пониженному уровню дезинтеграции соответствуют низкие показатели косвенной агрессии, негативизма, обиды, вербальной агрессии, чувства вины и агрессивности в общем, то группа с «врожденной инвалидностью» характеризуется тем, что пониженному уровню дезинтеграции соответствуют высокие показатели обиды и чувства вины. Результаты, полученные в группе с приобретенной инвалидностью, соответствуют данным И.А. Красильникова, согласно которому лица с высоким уровнем общей конфликтности ценностей по сравнению с лицами с низким уровнем характеризуются большей спонтанной агрессивностью (агрессивность импульсивного типа). При этом полученные в данном исследовании результаты относительно группы с врожденной инвалидностью не обнаруживают подобной связи.

\section{Выводы:}

1. Лица с врожденной инвалидностью по зрению обладают более низкими показателями агрессивности, чем лица с приобретенной инвалидностью.

2. Для лиц с врожденной инвалидностью более значимы ценности, центрированные на самореализации, тогда как для лиц с приобретенной инвалидностью - центрированные на приспособлении 
к группе. Так у первых на более значимых позициях находятся ценности смелость, исполнительность, удовольствие, а у вторых - терпимость и самоконтроль.

3. Каждая из исследуемых групп обладает специфическими корреляционными взаимосвязями показателей агрессивности и уровня дезинтеграции ценностно-мотивационной сферы. Группа с приобретенной инвалидностью по зрению характеризуется тем, что пониженному уровню дезинтеграции соответствуют низкие показатели косвенной агрессии, негативизма, обиды, вербальной агрессии, чувства вины и агрессивности в общем. Группа с врожденной инвалидностью характеризуется тем, что пониженному уровню дезинтеграции соответствуют высокие показатели обиды и чувства вины.

\section{Сиисок литературы}

1. Красильников И.А. Изучение влияния конфликтности ценностной сферы личности на адаптационный потенциал: Автореф. дис. ... канд. психол. наук. Саратов, 2005.

2. Литвак А.Г. Психология слепых и слабовидящих: Учебное пособие для студентов высших педагогических учебных заведений. СПб, 2006. $336 \mathrm{c}$.

3. Литвак А.Г. Очерки психологии слепых и слабовидящих. Ленинград: ЛГПИ им.А.И.Герцена, 1972. 224 с.

4. Лубовский В.И. Специальная психология. М.: Издательский центр «Академия», 2005. 464 с.

5. Методы исследования системы ценностных ориентаций: Методические указания для самостоятельной работы студентов всех направлений бакалавриата, изучающих курс «Социология и социальная психология» / Сост. Дулина Н.В., Токарев В.В., Василенко И.В. Волгоград: ВолГТУ, 1999. 36 с.

6. Мещеряков А.И. Слепоглухонемые дети. Развитие психики в процессе формирования поведения. М.: Педагогика, 1974.

7. Назарова Т.П. Мыслительная деятельность при слабовидении у младших школьников, при решении арифметических задач, Автореф. дис. ... канд. психол. наук. М., 1975. 
8. Райгородский Д.Я. Практическая психодиагностика. Методики и тесты. Самара: Издательский Дом «БАХРАХ-М», 2001. 672 с.

9. Фанталова Е.Б. Диагностика и психотерапия внутреннего конфликта. Самара: Издательский Дом «БАХРАХ-М», 2001. 128 с.

10. Херош С.М. Обучение слепых дошкольников опосредованной оценки различных свойств предметов. М., 1976.

11. Goldstein S. Encyclopedia of Child Behavior and Development. New York: Springer, 2011.

12. Hatlen P.H., Curry S.A. In support of specialized programs for blind and visually impaired children: The impact of vision loss on learning. Journal of Visual Impairment and Blindness, 81. 1987, pp. 7-13.

13. Hersen M., Kabacoff R.I., Van Hasselt V.B., Null J.A., Ryan C.F., Melton M.A., Segal D.L. Assertiveness, Depression, and Social Support in Older Visually Impaired Adults. Journal of Visual Impairment and Blindness, Nov-Dec. 1995, pp. 524-530.

14. Salleh N. M., Zainal K. How and why the visually impaired students socially behave the way they do. Procedia Social and Behavioral Sciences, 9. 2010, pp. 859-863.

15. Van Hasselt V. B. Social Adaptation in the Blind. Clinical Psychology Review, 3(1). 1983, pp. 87-102.

\section{References}

1. Krasil'nikov I.A. Izuchenie vliyaniya konfliktnosti tsennostnoy sfery lichnosti na adaptatsionnyy potentsial [Studying the influence of the conflict nature of the value sphere of the personality on the adaptation potential]. Saratov, 2005.

2. Litvak A.G. Psikhologiya slepykh i slabovidyashchikh: Uchebnoe posobie dlya studentov vysshikh pedagogicheskikh uchebnykh zavedeniy [Psychology of the Blind and Visually Impaired: A manual for students of higher pedagogical educational institutions]. SPb, 2006. $336 \mathrm{p}$.

3. Litvak A.G. Ocherki psikhologii slepykh i slabovidyashchikh [Essays on the psychology of the blind and visually impaired]. Leningrad: LGPI im.A.I.Gertsena, 1972. 224 p.

4. Lubovskiy V.I. Spetsial'naya psikhologiya [Special psychology]. M.: Izdatel'skiy tsentr «Akademiya», 2005. 464 p. 
5. Dulina N.V., Tokarev V.V., Vasilenko I.V. Metody issledovaniya sistemy tsennostnykh orientatsiy: Metodicheskie ukazaniya dlya samostoyatel'noy raboty studentov vsekh napravleniy bakalavriata, izuchayushchikh kurs «Sotsiologiya i sotsial'naya psikhologiya» [Methods of research of the system of value orientations: Methodical instructions for independent work of students of all areas of bachelor studying the course "Sociology and Social Psychology"]. Volgograd: VolGTU, 1999. 36 p.

6. Meshcheryakov A.I. Slepoglukhonemye deti. Razvitie psikhiki v protsesse formirovaniya povedeniya [The development of the psyche in the process of formation of behavior]. M.: Pedagogika, 1974.

7. Nazarova T.P. Myslitel'naya deyatel'nost' pri slabovidenii u mladshikh shkol'nikov, pri reshenii arifmeticheskikh zadach [Thoughtful activity with low vision in younger students, in solving arithmetic problems]. M., 1975.

8. Raygorodskiy D.Ya. Prakticheskaya psikhodiagnostika. Metodiki i testy [Practical psychodiagnostics. Techniques and tests]. Samara: Izdatel'skiy Dom «BAKhRAKh-M», 2001. 672 p.

9. Fantalova E.B. Diagnostika i psikhoterapiya vnutrennego konflikta [Diagnostics and psychotherapy of internal conflict]. Samara: Izdatel'skiy Dom «BAKhRAKh-M», 2001. 128 p.

10. Kherosh S.M. Obuchenie slepykh doshkol'nikov oposredovannoy otsenki razlichnykh svoystv predmetov [Teaching blind preschoolers mediated assessment of various properties of objects]. M., 1976.

11. Goldstein S. Encyclopedia of Child Behavior and Development. New York: Springer, 2011.

12. Hatlen P.H., Curry S.A. In support of specialized programs for blind and visually impaired children: The impact of vision loss on learning. Journal of Visual Impairment and Blindness, 81. 1987, pp. 7-13.

13. Hersen M., Kabacoff R.I., Van Hasselt V.B., Null J.A., Ryan C.F., Melton M.A., Segal D.L. Assertiveness, Depression, and Social Support in Older Visually Impaired Adults. Journal of Visual Impairment and Blindness, Nov-Dec. 1995, pp. 524-530.

14. Salleh N.M., Zainal K. How and why the visually impaired students socially behave the way they do. Procedia Social and Behavioral Sciences, 9. 2010, pp. 859-863. 
15. Van Hasselt V. B. Social Adaptation in the Blind. Clinical Psychology Review, 3(1). 1983, pp. 87-102.

\section{ДАННЫЕ ОБ АВТОРАХ}

Краснов Алексей Витальевич, доцент кафедры общей и клинической психологии, кандидат психологических наук Пермский государственньй национальный исследовательский университет ул. Букирева, 15, г. Пермь, 614990, Российская Федерация aleks-krasnov@yandex.ru

Баширова Эльвира Эдуардовна, выпускник кафедры общей и клинической психологии Пермский государственный национальньй исследовательский университет ул. Букирева, 15, г. Пермь, 614990, Российская Федерация

\section{DATA ABOUT THE AUTHOR}

Krasnov Aleksey Vitalyevich, Associate Professor at the Department of General and Clinical Psychology, PhD in Psychology Perm State University 15, Bukireva Str., Perm, 614990, Russian Federation aleks-krasnov@yandex.ru SPIN-code: 5173-6341 ORCID: 0000-0002-4242-2290

Bashirova Elvira Eduardovna, Graduate Student at the Department of General and Clinical Psychology Perm State University 15, Bukireva Str., Perm, 614990, Russian Federation 